\title{
ANALISIS POTENSI GERAKAN TANAH DI DESA SIRNARESMI KABUPATEN SUKABUMI
}

\author{
Josua Kelpin Nauli ${ }^{1}$, Yukiko Vega Subagio $^{2}$, Nabilla Kirana Mokoginta ${ }^{3}$ \\ 1,2,3 Jurusan Teknik Sipil, Fakultas Teknik, Universitas 17 Agustus 1945 Jakarta, Jl. Sunter Permai Raya, \\ Jakarta 14350 \\ siregarkelpin@yahoo.com,yukikovega03@gmail.com, nabillakirrana@gmail.com
}

\begin{abstract}
Geological phenomena of this kind is not the first time in the historical records, but still not maximizing the process of disaster management and the map of the land area of landslide caused by hilly geographical conditions, land Lanau, forest conditions planted Grain or crops, even by the human cause of illegal logging, as well. Therefore, this research aims to analyze the stability of slope based on data from the BPBD Sukabumi in the form of slope, morphology, class slopes, weight of the contents of land, soil cohesion and deep friction corners. The analysis was conducted with the help of GeoStudio 2012 software application. The results showed based on an analysis of 19 potentially landslides with a range SF 0530 - 0997 indicating the parameters used by the shear angle of $25^{\circ}$ and the soil weight of 13.4 $\mathrm{kN} / \mathrm{m}^{3}$
\end{abstract}

Keywords : Slope stability, Landslide, GeoStudio, Sukabumi.

\begin{abstract}
ABSTRAK
Fenomena geologi semacam ini bukan kali pertama dalam catatan sejarah, akan tetapi masih belum maksimalnya proses penanggulangan bencana dan rambu peta kawasan tanah longsor yang disebabkan kondisi geografis berbukit, tanah lanau, kondisi hutan yang ditanami padi-padian atau tanaman palawija, bahkan oleh sebab manusia sendiri dengan pembalakan liar. Oleh karena itu penelitian ini bertujuan untuk menganalisis stabilitas lereng berdasarkan data dari BPBD kabupaten Sukabumi berupa kemiringan lereng, morfologi, kelas lereng, berat isi tanah, kohesi tanah dan sudut gesek dalam. Analisis dilakukan dengan bantuan aplikasi software GeoStudio 2012. Hasil penelitian berdasarkan analisis 19 wilayah berpotensi longsor dengan range SF 0.530 - 0.997 menunjukkan parameter yang digunakan sudut geser $25^{\circ}$ dan berat isi tanah $13.4 \mathrm{kN} / \mathrm{m}^{3}$.
\end{abstract}

Kata kunci : Kemiringan lereng, Tanah longsor, GeoStudio, Sukabumi.

\section{PENDAHULUAN}

Di Indonesia, semenjak tahun 2000 banyak tempat di daerah yang berbukitbukit mengalami longsoran, terutama pada musim hujan (Hardiyatmo, 2006). Jawa barat merupakan salah satu wilayah yang sering mengalami suatu peristiwa geologi pergerakan tanah yang mengakibatkan dampak besar bagi populasi manusia. Lapisan yang terdiri dari tanah liat atau mengandung kadar liat akan bertindak sebagai peluncur (Arsyad, 1989). Provinsi Jawa Barat termasuk salah satu daerah yang memiliki potensi tinggi untuk terjadinya bencana tanah longsor. Hal ini disamping disebabkan oleh topografi wilayahnya yang berbukit dan bergunung, juga tingginya kepadatan penduduk yang menimbulkan tekanan terhadap ekosistem (Effendi, 2016).

Kawasan rawan longsor Provinsi Jawa Barat antara lain di Bandung, Cianjur, Bogor, Sukabumi, Majalengka, Sumedang, Ciamis, Tasikmalaya, Kuningan dan Purwakarta. Dilihat dari aspek demografinya, daerah tersebut merupakan kawasan padat penduduk (Direktorat Geologi dan Tata 
Lingkungan, 2002). Maka wilayah tersebut mempunyai dampak bagi para ahli untuk meneliti fenomena pergerakan tanah, pada musim hujan bulan oktober sampai dengan bulan Maret, disebabkan karena angin muson barat membawa banyak uap air, angin berpotensi menurunkan hujan, angin yang bergerak dari Asia menuju Australia sehingga hujan yang jatuh ke tanah selama periode tertentu diatas permukaan tanah terjadi evaporasi (menguap), run off (mengalir), infiltrasi (menyerap), kondisi tanah perbukitan menjadi tidak stabil menahan beban kondisi alam.

Penyebab tanah longsor secara alamiah meliputi morfologi permukaan bumi, penggunaan lahan, litologi, struktur geologi, curah hujan dan kegempaan. Selain faktor alamiah, longsor juga disebabkan oleh faktor aktivitas manusia yang mempengaruhi bentang alam seperti kegiatan pertanian, pembebanan lereng, pemotongan lereng dan penambangan (Somantri, 2014).

Desa Sirnaresmi, Kecamatan Cisolok, Kabupaten Sukabumi, Jawa Barat merupakan salah satu daerah di Indonesia dengan kondisi geografis yang terletak pada daerah dataran tinggi serta daerah pegunungan. Dengan kondisi geografis tersebut kecamatan Cisolok mempunyai data tanah yang tidak stabil dan kondisi mitigasi pascabencana kurang ditandai rambu peringatan dini.

Pada penelitian ini, akan dicoba untuk menganalisis stabilitas lereng dengan menentukan parameter dan range terjadinya longsor, mengetahui daerah daerah berpotensi dengan adanya keluaran bentuk pemetaan yang terdapat pada Kecamatan Cisolok dengan bantuan aplikasi software sejenis. Tujuan dari penelitian ini adalah untuk mengetahui dan mengimplementasikan hasil pemetaan.

\section{TINJAUAN PUSTAKA}

Pergerakan tanah berupa longsoran dari massa batuan/tanah adalah proses perpindahan suatu massa batuan/tanah akibat gaya gravitasi. Adanya gerakan tanah pada wilayah pemukiman yang dibangun didaerah perbukitan yang kurang memperhatikan kestabilan lereng, struktur batuan, dan proses geologi yang mungkin terjadi sering menimbulkan kerusakan bangunan, rumah, dan fasilitas umum (Noor, 2006).

Peta resiko (risk) longsor didapat dari peta potensi rawan (hazard) longsor yang kemudian diintegrasikan (overlay) dengan hasil analisis kerentanan (vulnerability). Analisis kerentanan itu sendiri merupakan hasil analisis berdasarkan parameter kepadatan penduduk (density), infrastruktur dan aksesibilitas. Zonasi kerentanan gerakan tanah menggunakan klasifikasi menurut Ward (1976) dalam Sugianti (2016), yang berdasarkan nilai faktor keamanan (FK) lereng, sebagaimana disajikan pada Tabel 1.1 hal ini karena belum ditemukan hasil penelitian terdahulu lainnya yang khusus menghasilkan klasifikasi zona gerakan tanah berdasarkan nilai FK lereng hingga saat ini.

Analisis stabilitas lereng menggunakan program GeoStudio 2012 dan disajikan pada Tabel 1.2

\section{METODE PENELITIAN}

\section{Waktu \& lokasi penelitian}

Penelitian analisis stabilitas lereng ini dilakukan pada April sampai dengan Mei 2019 di wilayah Desa Sirnaresmi, 
Kecamatan Cisolok, Kabupaten Sukabumi, Jawa Barat. Sebagai zonasi utama dalam penelitian kemudian di sertai survey kondisi di lain wilayah untuk parameter pembanding. Dapat dilihat pada Gambar 1 dan Gambar 2.

\section{Sumber dan teknik pengumpulan data}

Tahapan-tahapan dalam penelitian ini dapat digambarkan sebagai berikut:

1. Melakukan studi literatur peneliti terdahulu yang berkaitan dengan penelitian ini, seperti kategori ke stabilitas lereng, analisis tingkat resiko bencana longsor. Literatur tersebut diperoleh dari buku, jurnal, internet, serta penelitian terdahulu yang berkaitan dengan penelitian ini.

2. Melakukan pengumpulan data elevasi tanah, bentang longsoran, jenis tanah, sudut lereng dan tata guna lahan, data tersebut didapat berupa data sekunder untuk perhitungan, dimana data tersebut di peroleh dari Badan Penanggulangan Bencana Daerah (BPBD) Kabupaten Sukabumi. Data yang diberikan berupa peristiwa mitigasi pascabencana, peta shapefile dan parameter terkait lainnya.

3. Melakukan pengelompokan data tanah berdasarkan kategori wilayah, parameter yang diambil berdasarkan Tabel 2.1 dan Tabel 2.2.

4. Melakukakan analisis data kemiringan lereng, sudut gesek, elevasi tanah dan permeability yang didapat berdasarkan pada lokasi penelitian dengan bantuan software GeoStudio 2012, sehingga diperoleh data akurat sebagai pemetaan pada lokasi penelitian tersebut.

5. Membuat hasil pembahasan dan kesimpulan pada penelitian analisis stabilitas lereng di Desa Sirnaresmi Kabupaten Sukabumi. Langkah-langkah dalam penelitian ini terdapat pada Gambar 3.1 Bagan Alir Penelitian.

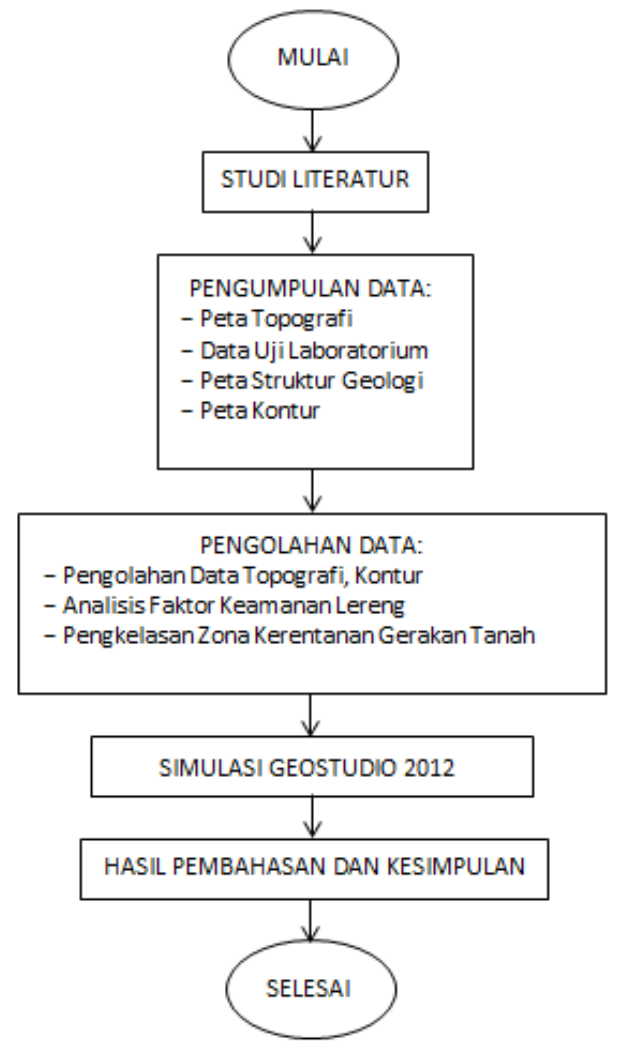

Gambar. 3.1 Bagan Alir Penelitian

\section{HASIL dan PEMBAHASAN}

Mengolah data tanah yang didapatkan dari pengamatan di masing - masing lokasi merupakan data jenis tanah, elevasi ketinggian lereng, menganalisis sudut gesek sisa menggunakan menurut Wesley, (2003) seperti disajikan pada Gambar 3.2 dan panjang longsoran, selanjutnya data tersebut dikelompokan dan kemudian dilakukan simulasi data dan analisis statistik data dengan menggunakan bantuan software GeoStudio 2012 untuk mendapatkan nilai slipsurface, factor of safety, total volume dan total activating force. GeoStudio merupakan program yang menyajikan data statistik untuk beberapa data masukkan saat pemetaan. Langkahlangkah analisis menggunakan GeoStudio adalah sebagai berikut: 
1. Membuka software, kemudian klik New Project-Create From This Template-Blank Document (default)Create.

2. Melakukan Add-SLOPE/W AnalyseLimit Equilibrium-Analysis TypeMorgenstern-Price or Spencer or Bishop or Janbu Method-Sett-Side Function-Constant Function-PWP Cond. From-Piez.Line-Ceklis Apply Phereati Correction-Close.

3. Setelah itu melakukan sketch axes (menentukan batas tinggi lereng mulai 0-xx dan menentukan panjang lereng mulai 0 -xx). Gambarkan sketsa bidang kondisi tanah-DrawRegions-Material-Slip Surface-Pore Water Pressure (muka air tanah 5-15 meter).

4. Demikian hasil input data selanjutnya masuk tahap Start-Simpan File-ViewSlide Mass.

5. Hasil dari analisis dapat dilihat pada menu Slide Mass, dan Slip Surface.

Metode Morgenstern-Price pertama digunakan untuk mencari SF tertinggi sampai terendah FK $<1.2$ - FK $>2.0$. berdasarkan klasifikasi.

Berdasarkan hasil analisis menggunakan GeoStudio, dapat dilihat pada tabel 3.1

\section{KESIMPULAN}

Dari pembahasan diatas, dapat diambil kesimpulan bahwa faktor keamanan $\leq$ 1.2 stabilitas lerengnya lebih dominan dan berpotensi sebanyak 19 wilayah. Berdasarkan Tabel 3.1 termasuk dalam kategori kerentanan tinggi.

\section{DAFTAR PUSTAKA}

[1] Effendi, A. Y., dan Hariyanto, T. 2016, Pembuatan Peta Daerah Rawan Bencana Tanah Longsor dengan Menggunakan Metode Fuzzy logic, Jurnal Teknik Institut Teknologi Sepuluh November, Vol. 5, No.2, Hal 714-722.

[2] BNPB, 2015. Data dan Informasi Bencana Indonesia. http://dibi.bnpb.go.id/. diakses tanggal 12 Mei 2015.

[3] Noor, Djauhari. 2006. Geologi Lingkungan. Yogyakarta: Graha Ilmu.

[4] Somantri, Lili. 2014. Kajian Mitigasi Bencana Longsor Lahan Dengan Menggunakan Teknologi Penginderaan Jauh. Makalah disajikan dalam seminar seminar Ikatan Geografi Indonesia di Padang, Tanggal 22-23.

[5] Arsyad, Sitanala. 1989. Konservasi Tanah dan Air. Bogor : Institut Pertanian Bogor.

[6] Peta Terdampak Longsor Cisolok Sukabumi, sumber: Akusisi Pesawat Tanpa Awak Tanggal 03 Januari 2019.

[7] Sugianti, K., Sukristiyanti., Tohari, A., 2016, Model Kerentanan Gerakan Tanah Wilayah Kabupaten Sukabumi Secara Spasial dan Temporial, Riset Geologi dan Pertambangan, Vol. 26, No.2, 117129.

[8] Ward, T. J., 1976. Factor of Safety Approach to Landslide Potensial Delination. Dissertation, Departement of Civil Engineering, Colorado State, Fort Collins, Colorado.

[9] Wesley, Laurence D., 2012, Mekanika Tanah untuk Tanah Endapan dan Residu, Penerbit Andi : Yogyakarta.

[10] Hardiyatmo, Harry C., 2006. Penanganan Tanah Longsor dan Erosi. Yogyakarta. Gadjah Mada University Press. 
Tabel 1.1 Klasifikasi kerentanan gerakan tanah (Ward, 1976 )

\begin{tabular}{cc}
\hline Kategori & Faktor Keamanan \\
\hline Kerentanan Sangat Rendah & FK $>2.0$ \\
Kerentanan Rendah & $2.0>$ FK $>1.7$ \\
Kerentanan Menengah & $1.7>$ FK $>1.2$ \\
Kerentanan Tinggi & FK $<1.2$ \\
\hline
\end{tabular}

Tabel 1.2 Analisis stabilitas lereng berdasarkan limit equilibrium dan slice method

\begin{tabular}{lllll} 
& & \multicolumn{2}{c}{ Method } & \multicolumn{3}{c}{ Equilibrium Equation } \\
\cline { 3 - 5 } No & & Horizontal & Vertical & Moment \\
\hline 1 & Fellenius (1927) & - & - & $\sqrt{ }$ \\
2 & Bishop' Simplified (1955) & $\sqrt{ }$ & $\sqrt{ }$ & $\sqrt{ }$ \\
3 & Janbu's Simplified (1954) & $\sqrt{ }$ & $\sqrt{ }$ & - \\
4 & Corps of Engineering (1982) & $\sqrt{ }$ & $\sqrt{ }$ & - \\
5 & Lowe and Karfiath (1960) & $\sqrt{ }$ & $\sqrt{ }$ & $\sqrt{ }$ \\
6 & Spencer (1967) & $\sqrt{ }$ & $\sqrt{ }$ & $\sqrt{ }$ \\
7 & Sarma (1973) & $\sqrt{ }$ & $\sqrt{ }$ & $\sqrt{ }$ \\
8 & Morgenstern and Price (1975) & & \multicolumn{3}{c}{. }
\end{tabular}

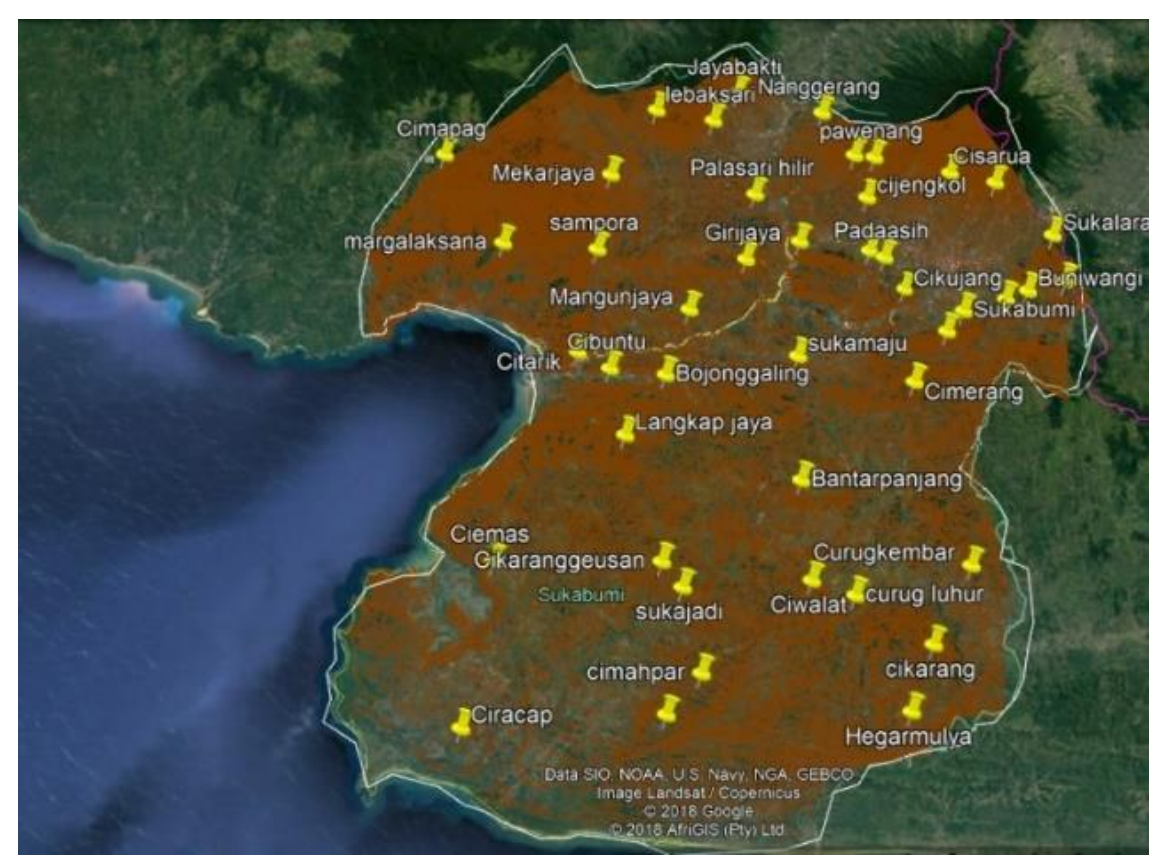

Gambar 1. Peta Berpotensi Tanah Longsor Sukabumi Sumber: Google Earth Pro 


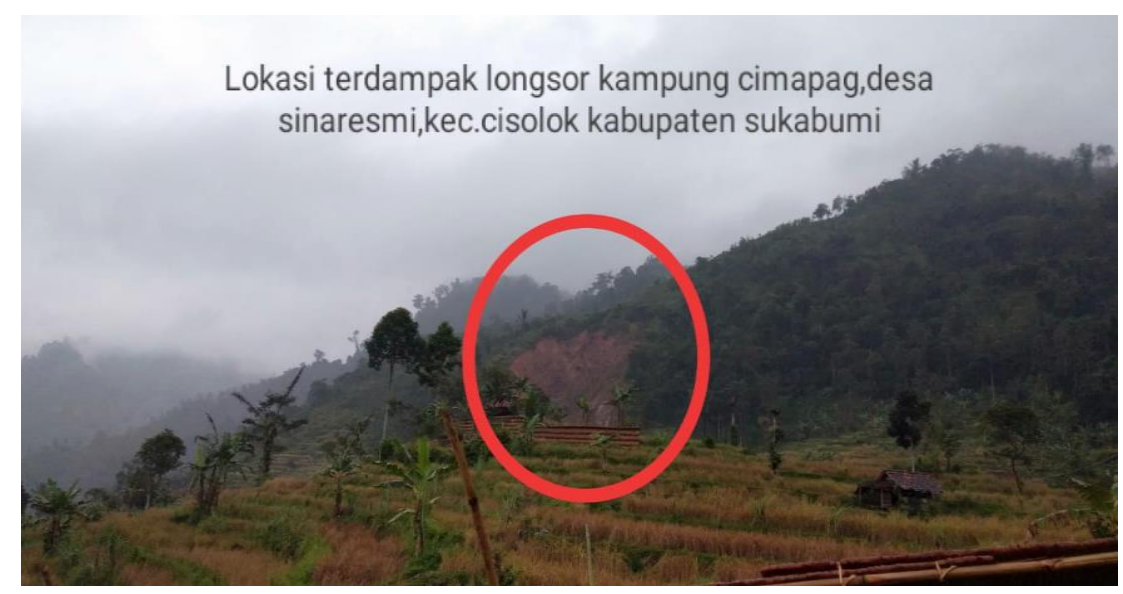

Gambar 2. Lokasi Kondisi Eksisting Kp. Cimapag, Desa Sirnaresmi, Kabupaten Sukabumi

Sumber: Dokumentasi Pribadi

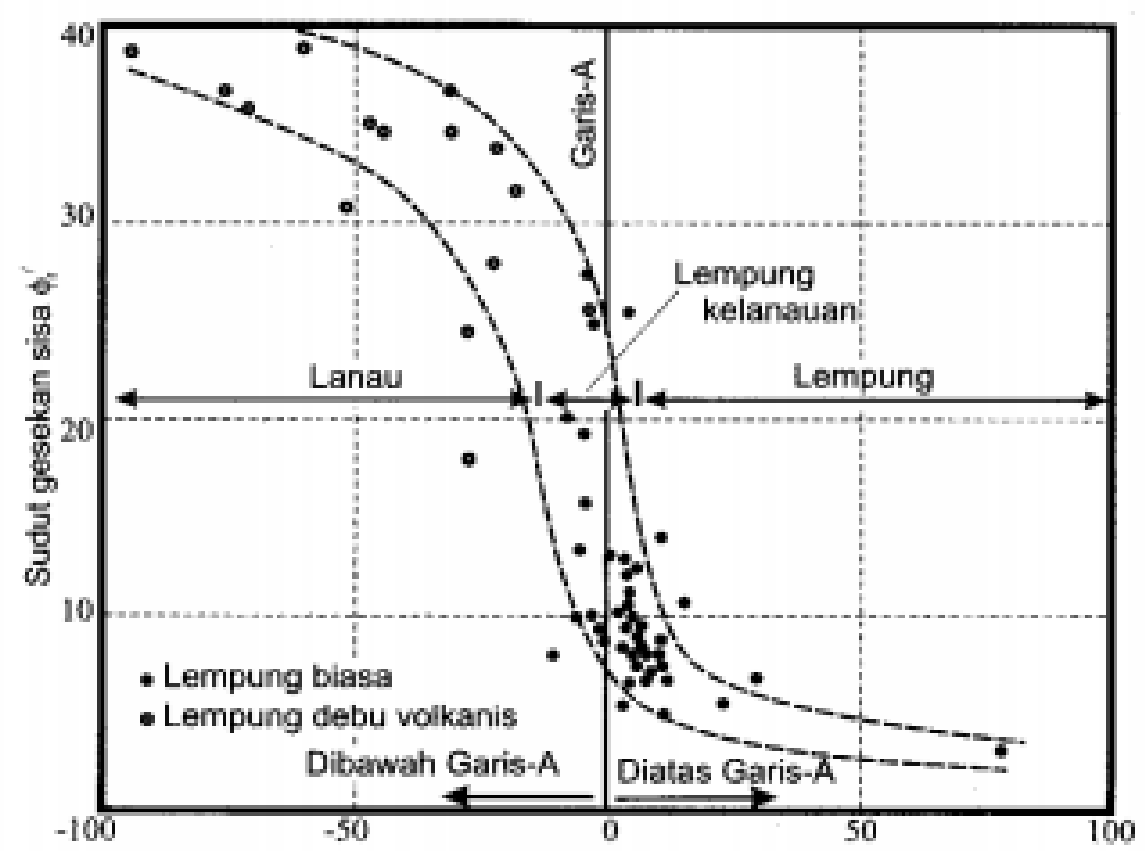

Gambar 3.2. Sudut gesek sisa $\varphi^{\prime}($ Wesley, 2003) 
Tabel 2.1 Klasifikasi Parameter Penentu Tidak Rentan

\begin{tabular}{cc}
\hline Parameter Keteknikan & Potensi Daerah \\
\hline Berat Isi (kN/m3) & 14.6 \\
Kohesi efektif $(\mathrm{kPa})$ & 19.62 \\
Sudut geser efektif $(\stackrel{\circ}{)})$ & 13 \\
Permeabilitas (m/det) & $4 \times 10^{-4}$ \\
\hline Sumber: Jurnal RISET Geologi dan Pertambangan, Vol.26, No.2, (Sugianti, 2016)
\end{tabular}

Tabel 2.2 Klasifikasi Parameter Penentu Rentan

\begin{tabular}{cc}
\hline Parameter Keteknikan & Potensi Daerah \\
\hline Berat Isi $(\mathrm{kN} / \mathrm{m} 3)$ & 13.4 \\
Kohesi efektif $(\mathrm{kPa})$ & 2 \\
Sudut geser efektif $\left(^{\circ}\right)$ & 25 \\
Permeabilitas $(\mathrm{m} / \mathrm{det})$ & $5 \times 10^{-2}$
\end{tabular}

Sumber: Jurnal RISET Geologi dan Pertambangan, Vol.26, No.2, (Sugianti, 2016)

Tabel 3.1 Hasil Analisis Software

\begin{tabular}{|c|c|c|c|c|c|c|}
\hline \multirow[b]{2}{*}{ Kecamatan } & \multicolumn{4}{|c|}{ Nilai SF } & \multirow[b]{2}{*}{$\begin{array}{l}\text { Indikasi } \\
\text { SF }\end{array}$} & \multirow[b]{2}{*}{$\begin{array}{l}\text { Kualifikasi } \\
\text { Kerentanan }\end{array}$} \\
\hline & $\begin{array}{l}\text { Morgenstern- } \\
\text { Price }\end{array}$ & Spencer & Janbu & Bishop & & \\
\hline Bantargadung & 0.530 & 0.530 & 0.414 & 0.504 & $\mathrm{SF} \leq 1.2$ & Tinggi \\
\hline Bojonggenteng & 0.732 & 0.732 & 0.648 & 0.719 & $\mathrm{SF} \leq 1.2$ & Tinggi \\
\hline Caringin & 0.922 & 0.922 & 0.814 & 0.923 & $\mathrm{SF} \leq 1.2$ & Tinggi \\
\hline Ciambar & 0.877 & 0.877 & 0.792 & 0.876 & $\mathrm{SF} \leq 1.2$ & Tinggi \\
\hline Cibadak & 4.286 & 4.286 & 4.160 & 4.288 & $S F \geq 2.0$ & $\begin{array}{l}\text { Sangat } \\
\text { rendah }\end{array}$ \\
\hline Cibitung & 1.032 & 1.032 & 0.890 & 1.032 & $\mathrm{SF} \leq 1.2$ & Tinggi \\
\hline Cimahi & 2.001 & 2.001 & 1.811 & 2.003 & $\begin{array}{l}2.0>S F \\
>1.7\end{array}$ & Rendah \\
\hline Cicurug & 1.639 & 1.639 & 1.596 & 1.639 & $\begin{array}{l}1.7>\mathrm{SF} \\
>1.2\end{array}$ & Menengah \\
\hline Hegarmulya & 1.940 & 1.940 & 1.905 & 1.940 & $S F \leq 1.2$ & Tinggi \\
\hline Cidahu & 2.472 & 2.472 & 2.396 & 2.474 & $S F \geq 2.0$ & $\begin{array}{l}\text { Sangat } \\
\text { rendah }\end{array}$ \\
\hline Cidolog & 4.213 & 4.213 & 4.064 & 4.213 & $S F \geq 2.0$ & $\begin{array}{l}\text { Sangat } \\
\text { rendah }\end{array}$ \\
\hline Ciemas & 1.138 & 1.138 & 1.111 & 1.138 & $\mathrm{SF} \leq 1.2$ & Tinggi \\
\hline Cikakak & 1.759 & 1.759 & 1.705 & 1.760 & $\begin{array}{l}1.7>\mathrm{SF} \\
>1.2\end{array}$ & Menengah \\
\hline Cikembar & 1.552 & 1.552 & 1.497 & 1.552 & $\begin{array}{l}1.7>\mathrm{SF} \\
>1.2\end{array}$ & Menengah \\
\hline & & 23 & & & & \\
\hline
\end{tabular}




\begin{tabular}{|c|c|c|c|c|c|c|}
\hline Cikidang & 0.800 & 0.800 & 0.738 & 0.799 & $\mathrm{SF} \leq 1.2$ & Tinggi \\
\hline Cimanggu & 2.272 & 2.272 & 2.194 & 2.273 & $S F \geq 2.0$ & $\begin{array}{l}\text { Sangat } \\
\text { rendah }\end{array}$ \\
\hline Ciracap & 2.730 & 2.730 & 2.640 & 2.730 & $S F \geq 2.0$ & $\begin{array}{l}\text { Sangat } \\
\text { rendah }\end{array}$ \\
\hline Cireunghas & 1.067 & 1.067 & 0.909 & 1.069 & $\mathrm{SF} \leq 1.2$ & Tinggi \\
\hline Cisaat & 3.049 & 3.049 & 2.804 & 3.052 & $S F \geq 2.0$ & $\begin{array}{l}\text { Sangat } \\
\text { rendah }\end{array}$ \\
\hline Cisolok & 0.733 & 0.733 & 0.704 & 0.729 & $\mathrm{SF} \leq 1.2$ & Tinggi \\
\hline Curugkembar & 2.456 & 2.456 & 2.301 & 2.458 & $S F \geq 2.0$ & $\begin{array}{l}\text { Sangat } \\
\text { rendah }\end{array}$ \\
\hline Gegerbitung & 1.218 & 1.217 & 1.094 & 1.211 & $\begin{array}{l}1.7>\mathrm{SF} \\
>1.2\end{array}$ & Menengah \\
\hline Gunungguruh & 2.342 & 2.342 & 2.341 & 2.279 & $S F \geq 2.0$ & $\begin{array}{l}\text { Sangat } \\
\text { rendah }\end{array}$ \\
\hline Djampang kulon & 1.361 & 1.361 & 1.316 & 1.361 & $\begin{array}{l}1.7>\mathrm{SF} \\
>1.2\end{array}$ & Menengah \\
\hline $\begin{array}{l}\text { Djampang } \\
\text { tengah }\end{array}$ & 1.512 & 1.512 & 1.510 & 1.512 & $\begin{array}{l}1.7>\mathrm{SF} \\
>1.2\end{array}$ & Menengah \\
\hline Kabandungan & 0.640 & 0.640 & 0.619 & 0.638 & $\mathrm{SF} \leq 1.2$ & Tinggi \\
\hline Kadudampit & 1.720 & 1.720 & 1.666 & 1.722 & $\begin{array}{l}2.0>\mathrm{SF} \\
>1.7\end{array}$ & Rendah \\
\hline Kalapanunggal & 0.741 & 0.741 & 0.715 & 0.740 & $S F \leq 1.2$ & Tinggi \\
\hline Kalibunder & 2.415 & 2.415 & 2.333 & 2.415 & $S F \geq 2.0$ & $\begin{array}{l}\text { Sangat } \\
\text { rendah }\end{array}$ \\
\hline Kebon pedes & 1.228 & 1.228 & 1.192 & 1.228 & $\begin{array}{l}1.7>\mathrm{SF} \\
>1.2\end{array}$ & Menengah \\
\hline Lengkong & 0.444 & 0.444 & 0.371 & 0.420 & $\mathrm{SF} \leq 1.2$ & $\begin{array}{l}\text { Sangat } \\
\text { rendah }\end{array}$ \\
\hline Nagrak & 1.382 & 1.382 & 1.339 & 1.382 & $\begin{array}{l}1.7>\mathrm{SF} \\
>1.2\end{array}$ & Menengah \\
\hline Nyalindung & 0.647 & 0.647 & 0.588 & 0.645 & $\mathrm{SF} \leq 1.2$ & Tinggi \\
\hline Pabuaran & 0.785 & 0.785 & 0.695 & 0.772 & $\mathrm{SF} \leq 1.2$ & Tinggi \\
\hline Pelabuhan ratu & 1.203 & 1.203 & 1.054 & 1.195 & $\mathrm{SF} \leq 1.2$ & Tinggi \\
\hline Parakan salak & 0.918 & 0.918 & 0.884 & 0.916 & $\mathrm{SF} \leq 1.2$ & Tinggi \\
\hline Parungkuda & 2.190 & 2.190 & 2.115 & 2.190 & $S F \geq 2.0$ & $\begin{array}{l}\text { Sangat } \\
\text { rendah }\end{array}$ \\
\hline Purabaya & 0.820 & 0.820 & 0.792 & 0.819 & $\mathrm{SF} \leq 1.2$ & Tinggi \\
\hline Segaranten & 0.786 & 0.786 & 0.719 & 0.786 & $\mathrm{SF} \leq 1.2$ & Tinggi \\
\hline Warungkiara & 1.329 & 1.329 & 1.141 & 1.330 & $\begin{array}{l}1.7>\mathrm{SF} \\
>1.2\end{array}$ & Menengah \\
\hline Simpenan & 1.603 & 1.603 & 1.500 & 1.605 & $\begin{array}{l}1.7>\mathrm{SF} \\
>1.2\end{array}$ & Menengah \\
\hline Sukabumi & 0.997 & 0.997 & 0.914 & 0.997 & $S F \leq 1.2$ & Tinggi \\
\hline
\end{tabular}




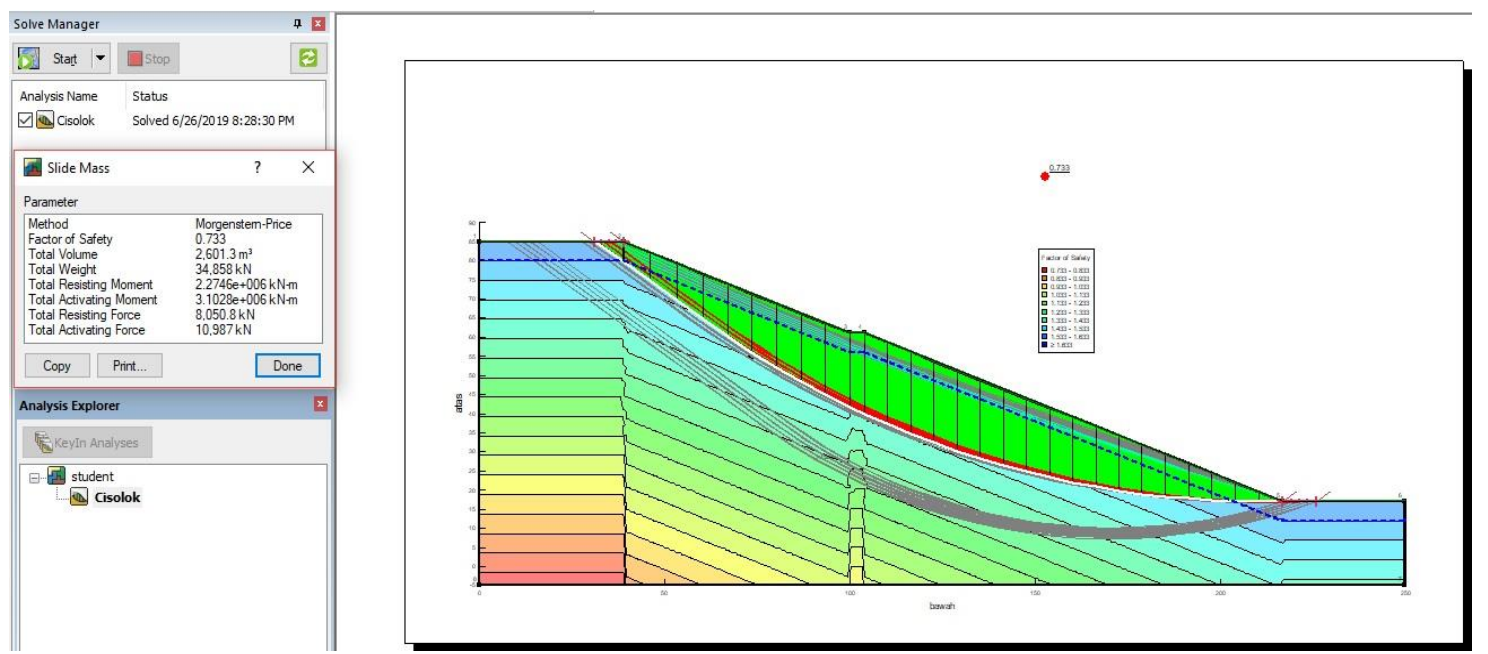

Gambar. 4 Hasil Perhitungan Metode Morgenstern-Price 
Josua Kelpin, dkk, Analisis Potensi Gerakan Tanah 